\title{
REA e Pomar: Desdobramentos de uma Educação Aberta na Cibercultura
} OER and Pomar: Unfolding of Open Education in Cyberculture

\footnotetext{
${ }^{1}$ Pós-doutora em educação pelo Instituto de Educação da Universidade de LisboaPT. Professora Associada do Departamento de Educação da Faculdade de Educação (FACED) e dos Programas de Pós-Graduação em Educação e em Gestão e Avaliação da Educação Pública da Universidade Federal de Juiz de Fora (UFJF). Endereço: Rua Profa. Aracy Nazareth, 01, Spina Ville II. Juiz de Fora - MG Brasil.arbruno@gmail.com

${ }^{2}$ Mestre em Educação pela Universidade Federal de Juiz de Fora (UFJF), especialista no Ensino Fundamental pelo Colégio de Aplicação João XXIII, da UFJF. Pesquisadora do Grupo de Pesquisa Aprendizagem em Rede/Faculdade de Educação/Universidade Federal de Educação. Estrada de Salvaterra, 4800. Juiz de Fora - MG - Brasil. carollsmattos@hotmail.com
}

Adriana Rocha Bruno*1, Ana Carolina Guedes Mattos²

\section{Resumo}

O presente texto apresenta conceitos e a compreensão das autoras acerca da Educação Aberta e também seus desdobramentos, a saber: recursos educacionais abertos (REA), massive open online courses (MOOC) e Percursos Online Múltiplos, Abertos e Rizomáticos (Pomar) como movimentos contemporâneos na/da educação. A dissertação - cuja natureza se deu a partir de uma revisão de literatura - defendida em março de 2015 no Programa de Pós-Graduação em Educação da Universidade Federal de Juiz de Fora (PPGE/UFJF) foi a base para as reflexões críticas tratadas no texto sobre tais temáticas. Os estudos de Gilles Deleuze e Felix Guattari sobre multiplicidade, devir, plano de imanência e rizoma são tratados como potencializadores para maximizar a complexidade da educação contemporânea. Os REA suscitam transformações singulares na medida em que fomentam o acesso ao conhecimento produzido e o compartilhamento de ideias, recursos e produtos. Destarte, oferecem múltiplas possibilidades de materiais em variados repositórios e formatos que podem ser (re)utilizados em realidades diversas. A incorporação de REA nas práticas educacionais passa a compor esse trajeto na Educação Aberta. Produzir e socializar, colaborativamente, desdobrar, dar/ter acesso, remixar, valorizar as múltiplas produções de conhecimento existentes e incorporá-las ao consumido e ao produzido é ser um educador/aprendiz aberto.

Palavras-chave: Educação Aberta, REA, Pomar, Cibercultura. 


\section{OER and Pomar: Unfolding of Open Education in Cyberculture}

\section{Abstract}

The present text exhibit concepts and the authors' understanding about Open Education and also its splits, namely: Open Educational Resources (OER), Massive Open Online Courses (MOOCs) and Multiples Open Online Roots and Rhizome (POMAR) as contemporary movements in education. The dissertation - the nature of which was based on a literature review - defended in March 2015, in the Postgraduate Program in Education of the Federal University of Juiz de Fora (PPGE I UFJF) was the basis for the critical reflections text on such topics. The studies of Gilles Deleuze and Felix Guattari about differentiation, becoming, immanence plan and rhizome are treated as potentiators to maximize the complexity of the contemporary education. OER bring unique transformations as they foster access to the produced knowledge and for sharing ideas, resources and products. Thus, they offer multiple possibilities of materials in various repositories and formats that can be (re) used in diverse realities. The incorporation of OER in educational practices is a part of this path in Open Education. Producing and socializing, collaboratively, deploying, giving-accessing, remixing, valuing multiple existing knowledge productions and incorporating them into the consumed and produced is to be an open educator / learner.

Keywords: Open Education, OER, MOOC, POMAR, Cyberculture.

\section{Conversando sobre o contemporâneo}

Os estudos acerca do contemporâneo e de conteúdos-temas que estão subjacentes a ele integram o movimento da Educação Aberta e da cibercultura'. Nesse cenário, as possibilidades atuais da Educação Aberta estão materializadas nas redes sociais online, nos recursos educacionais abertos (REA) e nos massive open online courses (MOOC); tais temáticas têm se constituído, respectivamente, como recurso e espaço da educação. Tais discussões oferecem campos férteis para as relações entre as tecnologias digitais em rede e a educação, cuja articulação traz implicações sociais, políticas e culturais.

A educação brasileira tem vivido uma época de desafios. A cibercultura - que transcende as denominadas "novas tecnologias" para uma concepção mais ampla de "atividade multiforme de grupos humanos" (Lévy, 1999, p. 28) - dentre outros aspectos, transforma os sentidos e significados de autoria, modificando as relações entre emissão e recepção, descentralizando o acesso ao saber, ao conhecimento, tornando-o disponível e favorecendo a produção e a socialização do conhecimento produzido por qualquer sujeito em todo o mundo.

Movimentos por uma educação aberta, livre e colaborativa passaram a integrar os debates educacionais e algumas ações já são socializadas, viabilizadas por espaços interativos online. Esse campo potente abriga as discussões propostas neste artigo, especialmente no que tangem à Educação Aberta e aos REA materializados na proposta de percursos formativos abertos na cibercultura. A pesquisa Formação Docente no Ensino Superior em Tempos de Cibercultura: Multiplicidade, Coaprendizagem e Educação Online,

1 O presente artigo foi produzido a partir da apresentação nos eventos: I) 37ª Reunião Nacional da Anped, Florianópolis/SC 2015; II) IX Simpósio Nacional ABCiber, São Paulo/SP, 2016. 
financiada pela Fapemig, iniciada em 2013 e finalizada em 2015, abarcou quatro eixos de investigação; o eixo 4 é aquele que abarcou os dados de uma pesquisa teórica em nível de mestrado defendida em 2015 no PPGE/UFJF e a produção de um protótipo de percursos formativos abertos, desenvolvido pelo Grupo de Pesquisa Aprendizagem em Rede - Grupar/UFJF, o denominado Pomar (Percursos Online Múltiplos Abertos e Rizomáticos).

Educação Aberta, segundo Inuzuka e Duarte (2012), é um movimento que visa tornar a educação "mais aberta e acessível a todos". Esse movimento ocorre há décadas, como o humanismo rogeriano. Porém um dos seus marcos está na Declaração da Cidade do Cabo, de 2007, que reafirma a crença na solidariedade da partilha de boas ideias entre educadores e a cultura da internet fundada na colaboração e interação, tendo como premissa também a liberdade no uso, aperfeiçoamento e reúso de recursos educacionais.

De acordo com Santos (2012b), na década de 1970 a Educação Aberta começou a ser discutida pelas universidades abertas e o conceito foi se adaptando à nova realidade da sociedade hodierna. Essa compreensão de Educação Aberta integra-se também aos estudos de Otto Peters (2004), em que o autor, já na década de 1970, indicava o que seria a nova era da Educação a Distância, com o uso de eletrônicos analógicos (rádio e televisão) e, mais tarde, dos vídeos e das fitas cassete como fortes aliados para o acesso ao conhecimento.

Como anunciado, uma das bases da Educação Aberta está, para nós, associada à Educação humanista de Rogers (1997), que propõe uma educação descentralizadora, cujo processo de aprendizagem seja protagonizado pelo aprendiz ao trilhar seu trajeto como sujeito ativo e responsável pela sua aprendizagem. Esse tipo de abordagem forja a potencialidade de produzir processos formativos abertos, participativos e colaborativos na medida em que os sujeitos implicados na aprendizagem assumem-se como corresponsáveis pelos percursos cocriados.

A noção de Educação Aberta cria, notadamente, formas muito singulares de se relacionar e de produzir/consumir conhecimentos. Santos (2012b) propõe características da Educação Aberta e da liberdade do estudante no que tangem às reconfigurações do sujeito epistemológico. De acordo com a estudiosa, I) o estudante tem a liberdade de escolher o lugar no qual irá estudar (casa, trabalho ou instituição de ensino); II) pode estudar por módulos, créditos, ou qualquer forma que auxiliar o estilo de vida do estudante; III) pode fazer uso da autoinstrução com base em uma certificação opcional; IV) pode obter isenção de taxas de matrícula ou mensalidade para a realização do curso desejado; V) pode obter isenção de processos seletivos e de qualificações prévias; VI) pode fazer uso de REA na educação formal ou informal (Santos, 2012b, p. 74).

Nada de muito novo se considerarmos os estudos realizados pelo menos desde os anos 1990. Porém as mudanças, em nosso entender, e em certa medida em discordância com Santos (2011), são significativas se considerarmos alguns aspectos, como os apresentados por Bruno e Mattos (2016): a) o protagonismo que agora não está no estudante nem no docente, mas de fato no processo que implica a aprendizagem; b) a perspectiva real de abertura, que envolve acesso ao conhecimento produzido, acesso a condições de produzir conhecimento, acesso às tecnologias digitais em rede, descentralização do ensino considerando o estudante adulto efetivo parceiro; c) coerência epistemológica freiriana; d) produção e experienciação de rede de aprendizagem; dentre outros aspectos.

O exemplo mais conhecido de universidade aberta é a Open University do Reino Unido, que oferece ao participante o estudo por módulos, a certificação obtida por créditos e a não pré-requisitação. Ainda que o nome se assemelhe à Universidade Aberta do Brasil (UAB), uma nada tem a ver com a outra no que se compreende por abertura. Na UAB há processo seletivo, cronograma fechado, ambiente virtual de aprendizagem (AVA) específico, pré-requisitação, modelo pedagógico condicionado por planilhas e verbas federais etc. Trata-se de um tipo de Educação a Distância (EaD) 
pública, que dá aos brasileiros acesso ao ensino gratuito de qualidade, com polos presenciais próximos às suas residências e dimensões espaço-temporais flexíveis para dedicação aos estudos.

A abertura tratada neste artigo é diferente da referida na UAB-Brasil. A Educação Aberta implica liberdade pedagógica e autonomia financeira para produção de espaços de aprendizagem. Isso envolve socialização, remixagem, coprodução/coautoria dos materiais a serem disponibilizados para e produzido por/com os estudantes; nessa direção, os REA são agenciadores e possibilitadores de que esse tipo de educação ocorra. É sabido que, em diversos cursos dito abertos, são utilizados recursos mais fechados, como os objetos de aprendizagem. Entretanto, se buscarmos a coerência epistemológica e prática do que propomos como Educação Aberta, a consciência de abertura deve ser ampliada para além da socialização de recursos e materiais, convergindo com ideias, design e ações mais colaborativas e parceiras.

Os REA carregam a concepção de abertura, que inclui "uso, reúso, revisão, remix e redistribuição, bem como facilidades técnicas de adaptação" (Amiel; Orey; West, 2010, p. 115). No Brasil, a comunidade de recursos educacionais abertos toma por base definições de REA da Unesco: “materiais de ensino, aprendizado e pesquisa, fixados em qualquer suporte ou mídia, que estejam sob domínio público ou licenciados de maneira aberta, permitindo que sejam usados ou adaptados por terceiros" (Inuzuka; Duarte, 2012, p. 196).

Em seus estudos, Pretto (2012) menciona que os REA promovem exercícios de autonomia para os sujeitos, que passam a ter acesso a materiais que podem/devem ser modificados, e ressalta a importância da liberdade para alterar/mixar dados e materiais. O uso dos REA, nessa direção, vai além do simples acesso ao conteúdo e à possibilidade de reutilização, pois provoca uma cultura de socialização, alteração de materiais e partilhas, conforme a demanda de cada pessoa, e até mesmo plataformas abertas para o compartilhamento de materiais, recursos e ideias.

\section{Caminhos e Reflexões}

O contato com os estudos de Gilles Deleuze e Felix Guattari $(1995,1998)$ despertou o nosso olhar para algumas acepções: multiplicidades, devires, plano de imanência e rizoma, potências para a compreensão dos acontecimentos das redes sociais de aprendizagem e seus desdobramentos.

As multiplicidades, em Deleuze e Guattari (1995), são peças que compõem “objetos parciais", são realidades que não desconsideram nem perdem o todo. A filosofia deleuziana rejeita a ideia de uno; portanto, não podemos compreender a multiplicidade como a somatória de unidades. "A multiplicidade não deve designar uma combinação de múltiplo e de um, mas uma organização própria do múltiplo enquanto tal, que não tem necessidade alguma da unidade para formar um sistema" (Deleuze, 1998, p. 236). Ao pensarmos na multiplicidade, ponderamos que Deleuze e Guattari (1995, p. 15) anunciam a composição de dimensões que se englobam e recapturam umas às outras em graus distintos aos anteriores. Multiplicidades são realidades, são acontecimentos que podem ocorrer ao mesmo tempo ou em tempos distintos, mas um fato não elimina a importância de todas as realidades.

Por sua singularidade, as multiplicidades conduzem a outro conceito, os rizomas. A ideia de rizoma foi tratada por esses filósofos por meio do empréstimo dos estudos da botânica. Rizoma é uma pseudorraiz que não possui um formato comum às outras raízes: cada ramificação pode ser diferente e crescer por caminhos distintos. Ele não é uno (n) nem múltiplo, mas feito de dimensões, de direções que se alteram. Diferentemente de uma constituição arbórea, que possui raízes estruturadas e facilmente controláveis, um rizoma é aberto, imprevisível e incontrolável. Daí sua importância e a relação com o presente estudo.

Mas conceitos, para Deleuze, são produções do acontecimento e são forjados no que ele denomina como plano de imanência, ou seja, algo diverso composto por pensamentos, com o caos do que não sabemos: "é necessariamente um plano de imanência e de univocidade. Vamos chamá-lo então plano de 
natureza, embora a natureza nada tenha a ver com isso, uma vez que esse plano não faz nenhuma diferença entre o natural e o artificial" (Deleuze; Guattari, 1995, p. 326). Dessa maneira, são embates entre o que sabemos e o que ainda não conhecemos se transformando em algo suplementar. Gallo elucida que "o plano de imanência é essencialmente um campo onde se produzem, circulam e se entrechocam os conceitos" (Gallo, 2008, p. 44).

As incertezas permeiam a nossa existência, e no desenvolvimento de pesquisas produzimos noções, conceitos, ideias; convivemos com achados, certezas, inferências e embates entre o que pensamos, o que é e o que será. O devir.

Deleuze e Guattari (1995) apresentam a ideia de devir como o conteúdo próprio do desejo. Desejar é passar por devires, e um devir não é um sonho, mas sim o encontro de dois termos heterogêneos que se desterritorializam: “Devir é nunca imitar nem fazer como nem se conformar a um modelo, seja de justiça, seja de verdade. Não há um termo do qual se parta nem um ao qual se chegue ou ao qual se deva chegar. Tampouco dois termos intercambiantes" (Deleuze, 1998, p. 22). O devir possibilita outra forma de viver e de sentir. O devir é descrito por Deleuze e Guattari (1995, p. 14) da seguinte maneira: “Um devir não é uma correspondência de relações. Mas tampouco é ele uma semelhança, uma imitação e, em última instância, uma identificação". O devir é algo que emerge do próprio desejo. O devir não generaliza situações, não indica a concretude. Ele representa uma realidade que não se repete, mas que relaciona dois termos heterogêneos que se transformam em outra realidade a partir dessa relação.

Nas reflexões realizadas acerca da temática do contemporâneo e da educação precisamos ter esse pensamento de devires, de possibilidades para potencializar a criação de planos de imanências e de redes rizomáticas (Bruno, 2010). Destarte, pensando na rede e nos desdobramentos de cursos e espaços de aprendizagem na realidade brasileira, sentimo-nos provocados pelos conceitos de Deleuze e Guattari (1995), cujas proposições inspiraram (não fundamentaram) as análises e as interpretações desenvolvidas. A investigação realizada em nível de mestrado e parcialmente apresentada aqui se constituiu num campo de imanência, de produção de ideias e de espaço de devires em que não há verdades, mas multiplicidades; em que os achados não são definitivos, mas rizomáticos.

O investigador, portanto, relaciona o olhar para o outro, o seu lugar social, as produções do campo e (re)constrói sentidos para eles, compreendendo a si, os sujeitos e seu contexto. Nesse momento, estamos lidando com os devires (Deleuze; Guattari, 1995). Logo, os pensamentos de todos os envolvidos não constituem uma semelhança, mas formulações que promovem outros devires, sem linearidade, mas por meio de rotas de fuga, são rizomáticos. Convergentes com a abertura, a pesquisa e a Educação abertas implicam ser abertas a ideias, a propostas criativas e inovadoras, a formatos múltiplos, a concepções abertas, a modalidades articuladoras, a tecnologias diversas; mas, principalmente nesse contexto, a abertura implica processos inclusivos, de acessibilidade, ubiquidade, hibridismo, conectividade, mobilidade. A abertura está na atitude de pesquisadores, educadores, gestores e estudantes que mudam suas formas de pensar e agir em sociedade e, assim, suas interações/relações com o outro.

Trata-se, então, de um "acontecimento", no sentido deleuziano: “O acontecimento não é o que acontece (acidente), ele é no que acontece o puro expresso que nos dá sinal e nos espera, [...] ele é o que deve ser compreendido, o que deve ser querido, o que deve ser representado no que acontece" (Deleuze, 2011, p. 152).

Não é um tipo de educação ou uma modalidade, ou um momento, um modismo, mas aqui a compreendemos como ação. É uma educação plástica, flexível, rizomática (Bruno, 2010; 2016), que não possui um dentro e um fora, mas um dentrofora, dobras, rotas, trajetos, travessias (in)visíveis. 


\section{Recursos Educacionais Abertos: Potências em Tempos de Educação Aberta}

O termo REA, conforme Santos (2012), foi pensado em um Fórum da Unesco sobre os cursos abertos na Educação Superior nos países em desenvolvimento. Amiel (2011) destaca que dois princípios devem ser considerados nos REA: "licença de uso que permita maior flexibilidade e uso legal de recursos didáticos; e abertura técnica, no sentido de utilizar formatos de recursos que sejam fáceis de abrir e modificar em qualquer software" (Amiel, 2011, p. 4).

Para a criação de REA é necessário que: I) o recurso apresente a licença credenciada para que o usuário saiba o que pode fazer para remixá-lo; II) o usuário possa modificar, compartilhar ou adaptar o REA da maneira como achar conveniente; e III) os formatos dos materiais sejam simples e fáceis de serem modificados (Santos, 2011).

Devemos ter cuidado em diferenciar objeto de aprendizagem e REA: o primeiro é fechado, pensado para o participante utilizá-lo sozinho, sem alterações em seu conteúdo; o segundo é disponibilizado para que o participante reconstrua o material, utilizando a cocriação e a colaboração presentes nos usuários da rede.

Para Amiel (2011), ao pensarmos nos REA, valorizamos a disponibilização de conteúdo na rede, com a licença adequada; ele, porém, alerta que o acesso aos materiais não é o único fator para garantir uma educação aberta. O estudioso adverte que o apoio ao estudante a partir da escolha de uma metodologia adequada e a criação de políticas públicas que incentivem o uso dos REA vão possibilitar o uso consciente desses recursos.

Ao pensar no licenciamento e, consequentemente, nos direitos autorais, é necessário considerar: I) o programa ou local utilizado para fazer o licenciamento; II) o tipo de licenciamento mais adequado ao material e ao conteúdo vinculado a ele; e III) Esclarecer o usuário para essas questões de reutilização.

Com relação ao licenciamento, a iniciativa do Creative Commons (CC), fundado em 2001, tem obtido aceitação na rede no que diz respeito à liberação dos materiais produzidos nela. As licenças são apresentadas no site, orientando os criadores e os cocriadores quanto aos limites e aberturas de cada permissão. O autor do material pode licenciar o seu recurso para qualquer uso, somente não comercial, ou autorizar a utilização desde que as liberdades sejam mencionadas posteriormente.

Os REA potencializam o acesso ao conhecimento e o compartilhamento de ideias, uma vez que oferecem múltiplas possibilidades de materiais em variados repositórios e formatos que podem ser utilizados em realidades diversas, a partir da demanda. Esse movimento ainda não está totalmente conhecido no Brasil; por isso, temos que incentivar sua disseminação por meio de produções acadêmicas que reflitam os benefícios dos recursos; problematizar as questões de abertura e direito autoral; e utilizar as políticas públicas de fomento à tecnologia para difundir o movimento dentro e fora do campo educacional.

\section{Educação Aberta na prática: Pomar}

Em contextos educativos, concepções de aprendizagem estão sempre subjacentes às práticas neles desenvolvidas, e a Educação Aberta tem sido associada ao conectivismo, termo cunhado por George Siemens e Stephen Downes (segundo Inuzuka; Duarte, 2012), que está baseado nas seguintes premissas: autonomia, diversidade, grau de abertura, conectividade e interatividade. No conectivismo, o aprendizado é pessoal e único, e o aluno é visto como cocriador e modificador de recursos, criador de estratégias de produção de conhecimento. 
A partir desses estudos, que incluiu também análises dos massive open online courses (MOOC) por meio da pesquisa de Mattos (2015), emergiu a questão: como produzir ambientes de aprendizagem que integrem a Educação de abertura e os REA, de modo a promover adultos críticos e que constituam redes rizomáticas?

Essa questão materializou os desejos de nosso grupo de pesquisa e ofereceu a oportunidade de colocar em prática nossas ideias: produzir redes rizomáticas, ou seja, criar "espaço para a invenção do pensamento, individual e coletivo, um espaço em que seja possível fomentar a formação de redes com hastes e rotas de fuga, a ampliação de redes e o questionamento das redes" (Bruno, 2010, p. 186).

A partir desse momento canalizamos nossas forças para criar ambientes para o desenvolvimento de percursos formativos abertos, o que foi denominado Pomar (Percursos Online Múltiplos Abertos e Rizomáticos).

A proposta de percursos formativos abertos na cibercultura se desenvolve em meio a e é promovido por um cenário mundial plural, em que múltiplas tecnologias e ideias convergentes se integram a estudos e conceitos produzidos no cerne das investigações do Grupar. A cibercultura, intensamente debatida e investigada por autores como Lévy (1999), Lemos (2004), Santaella (2004), Santos (2005), Silva (2009), dentre outros, sustenta as bases de nossas pesquisas, auferindo às produções empreendidas, tanto no campo teórico quanto no campo empírico do Grupar, os aprofundamentos necessários para compreensão das mudanças nos ambientes educacionais digitais e em rede na contemporaneidade.

A intenção de dar acesso a múltiplos conhecimentos e estimular a produção de conhecimentos entre os participantes leva à proposição dos percursos formativos, que diferem de curso; este pressupõe uma estrutura curricular definida, com conteúdos, estratégias, avaliação, tempo de início e término etc. A proposta da criação de Pomar é que cada integrante navegue pelo espaço de aprendizagem da maneira que achar mais potente, de acordo com os seus interesses pelas temáticas disponibilizadas num Pomar que escolher acessar. Um Pomar abriga múltiplos Pomar, um dentro do outro, cada um com diversos temas e subtemas e abordagens plurais, de forma rizomática. Cada membro é corresponsável por seu percurso; cria sua trajetória, consome conhecimentos e materiais disponibilizados, produz materiais e os socializa. O Pomar é uma proposta de criação de espaços abertos de aprendizagem. Até o momento foram criados dois Pomar: o primeiro, em 2014-2015, no Grupar, intitulado Pomar: Docências²; o segundo, em 2016, na disciplina Literacia Digital, ministrada pela líder do Grupar, Dra . Adriana Rocha Bruno, para a Universidade Aberta de Portugal: Pomar: Instituto Politécnico de Castelo Branco (IPCB)3.

O Pomar Docências nasceu da necessidade da criação de um espaço online e formativo impulsionada pela variedade de temas estudados pelos integrantes do grupo. Para seu desenvolvimento, resolvemos nos agrupar em equipes a partir de temas de interesse: Docência no ensino superior; Avaliação e educação; Tecnologias digitais da educação e comunicação (TDIC) e Educação; e Formação e subjetividade humana. Cada equipe de pesquisadores organizou e planejou o design, materiais e provocações que seriam disponibilizados de acordo com o tema e a maneira como seriam apresentados ao público. Este Pomar foi cocriado em um site gratuito que oferece variadas propostas de leiaute, ampliando a criação e a elaboração do que cada grupo gostaria de compartilhar na web.

Cada temática do Pomar Docências tem como intenção a problematização, a cocriação e a colaboração, criando um espaço de debate crítico e de constante construção. Os participantes podem criar subtemas e/ ou colaborar com os já existentes e abrir espaços de discussão e interagir com quem estiver interessado em dialogar sobre o que foi proposto. Dentro da temática TDIC e Educação, por exemplo, o participante

2 http://gruparufjf.wixsite.com/pomardocencias

3 http://ipcastelobranco.wixsite.com/pomar 
poderá acessar textos, vídeos, REA e fórum de discussão que devem ser alimentados e mediados pelos participantes, ou seja, a rede alimenta os Pomar.

Do mesmo modo, o Pomar criado por docentes do Instituto Politécnico Castelo Branco, em Portugal, num curso de formação online da UAB-PT, atendeu às demandas desses docentes em ampliar os espaços de diálogo e socialização de conteúdos e materiais tanto com outros docentes quanto com alunos. Os alunos do curso, após estudar sobre Educação e percursos abertos, produziram seus Pomar por áreas interdisciplinares, e assim surgiu o Pomar IPCB.

Por ser uma obra aberta, o Pomar está em constante construção e se alimenta das produções dos que acessam o ambiente e contribuem com questões e também materiais ou temas/subtemas, se desejarem.

Os Pomar são ambientes colaborativos abertos, de acesso, produção e socialização de informações e de conhecimentos. Visam à participação ilimitada e livre das pessoas que se abrem à aprendizagem colaborativa e autônoma - por meio da interação sujeito-web. Nos Percursos, os interessados criam seus próprios e singulares trajetos, caminhos. Pelas potencialidades dos ambientes online, tudo e todos estão "em conexão", e podem-devem cocriar redes. Tais relações interativas são múltiplas, no sentido da multiplicidade deleuziana, que possibilita níveis de intensidade e aprofundamento das temáticas/conteúdos abordados para/por/com qualquer pessoa que tenha interesse nos temas produzidos, bem como na cocriação de outras temáticas interligadas.

Por fim, são abertos e rizomáticos em sua convergência com os pressupostos da Educação Aberta e de REA, pois os Pomar não possuem começo, meio e fim, já que cada um pode acessar o que quiser e como quiser; e fomentam a prática dos REA. Tal como os rizomas não são estruturados, não são fixos e se retroalimentam da própria rede.

A pesquisa e a proposta do Pomar, em meio à cibercultura, evocam novas formas de ensino e de aprendizagem por meio da partilha, da construção colaborativa e da abertura no acesso. $O$ incentivo e a disseminação dessas ideias e práticas implicam a reflexão e a prática libertadora e democrática de fazer educação, bem como tensionar os debates acerca de questões como abertura e direito autoral; políticas públicas e de fomento à tecnologia para promoção de movimentos dentro e fora do campo educacional.

\section{Considerações: Reflexões e Outras Possibilidades}

Compreendemos que a Educação Aberta traz a possibilidade de fazer educação sem barreiras, sem limitações. Por que uma educação centrada no estudante? Por que uma educação centrada no professor? Por que uma educação centrada em sujeitos, espaços? A Educação contemporânea traz a potência de um processo múltiplo, em que a cocriação seja de fato "com", participativa, colaborativa, em que todos sejam mentores, articuladores, autores e estejam implicados no processo. Mais do que uma educação centrada num ator, num sujeito específico, precisamos cocriar educações descentralizadas, em que as polaridades e as cisões não mais existam.

Para que a Educação Aberta 'aconteça', a incorporação de recursos educacionais abertos passa a ser parte desse trajeto. Produzir e socializar, colaborativamente, desdobrar, dar-ter acesso, remixar, valorizar as múltiplas produções de conhecimento existentes e incorporá-las ao consumido e ao produzido é ser um educador/aprendiz aberto. Não se trata de fazer uso dos REA, mas de pensar e agir de modo que a abertura seja o sentido do sujeito. O contemporâneo implica novas formas de ensino e de aprendizagem por meio da partilha, da constru- 
ção colaborativa e da abertura no acesso, como na proposta apresentada pelo Pomar Docências ${ }^{4}$. Esse ambiente, protótipo aberto iniciado em 2014 e em recorrente mudança, tem sido fonte das investigações realizadas pelo Grupar. Não se trata de um exemplo ou modelo, mas de um campo de estudos e pesquisas, aberto, que se fará mais potente na medida em que outros pesquisadores e interessados habitarem esse espaço e produzirem outros Pomar. É preciso problematizar as questões de abertura e autoria; utilizar as políticas públicas de fomento à tecnologia para difundir o movimento de abertura dentrofora do campo educacional.

Os conceitos de multiplicidade, de devir, de plano de imanência e de rizoma apresentados por Deleuze e Guattari (1995) são relevantes no processo de reflexão da Educação Aberta e suas possibilidades. Estamos em constantes devires e o desenvolvimento do Pomar se deu em meio ao plano de imanência cocriado no/ pelo/com o grupo de pesquisa. Como tudo está/é aberto, inclusive a ideia de abertura, apenas o sabermos ser rizomáticos, inconclusos e múltiplos torna possível a coerência epistemológica desse percurso.

Estamos, portanto, tratando de outras formas de compreender o sujeito e a ação de educar e de aprender. A Educação Aberta resgata o lugar de ação do sujeito como aquele que age, faz, produz, comunica, se relaciona. Os REA são desdobramentos em coerência à concepção de sujeito como ser da ação e do pensamento que está conectado, em rede, aos outros sujeitos do mundo e, portanto, não centraliza, não controla, mas socializa, partilha, abre-se para o mundo.

\section{Referências Bibliográficas}

Amiel, T. (2011). Recursos educacionais abertos (REA): um caderno para professores. Educação Aberta, Campinas. Disponível em http://reaparana.com.br/portal/wp-content/uploads/2014/10/Recursos-Educacionais-Abertos-um-caderno-para-professores-2011.pdf

Amiel, T., Orey, M. \& West, R. (2010). Recursos educacionais abertos (REA): modelos para localização e adaptação. Educação Temática Digital, número especial: Tecnologias na Educação, p. 112-125. Disponível em http://periodicos.sbu.unicamp.br/ojs/index.php/etd/article/view/1206

Bruno, Adriana Rocha (2016). Pomar (Percursos Online Múltiplos, Abertos e Rizomáticos): espaços de coproduções para as docências e aprendências. Capítulo produzido a partir de palestras proferida no evento SIED-UFSCar/2014, para o livro organizado por Aline Reali e Daniel Mill. Editora UFSCar. No prelo.

Bruno, Adriana Rocha (2010). Travessias invisíveis: plasticidade, diferença e aprendizagem em redes rizomáticas de formação de adultos educadores nos ambientes online. In XV Endipe - Didática e prática de ensino: convergências e tensões no campo da formação e do trabalho docente, v. 2, pp. 171-196. Belo Horizonte, MG: Autêntica. Disponível em http://www.fae.ufmg.br/endipe/livros/Livro 3.PDF

Bruno, Adriana Rocha, Mattos, Ana Carolina G. (2016). Percursos formativos abertos na cibercultura. In IX Simpósio Nacional ABCiber. São Paulo, SP. Disponível em http://abciber.org.br/simposio2016/ trabalhos_aprovados

Deleuze, G. (2011). Lógica do sentido. São Paulo: Perspectiva.

Deleuze, G. (1998). Diferença e repetição. São Paulo: Graal.

Deleuze, G. \& Guattari, F. (1995). Mil platôs: capitalismo e esquizofrenia. v. 1. Trad. A. G. Neto \& C. P. Costa. São Paulo: Editora 34 (Coleção Trans).

Gallo, S. (2008). Deleuze \& a educação. $2^{\text {a }}$ ed. Belo Horizonte: Autêntica.

4 Para conhecer/acessar o primeiro Pomar, acesse: http://gruparufjf.wixsite.com/pomardocencias. Vale lembrar que esse ambiente aberto de aprendizagem está e sempre estará em construção e tem sido foco dos estudos do Grupar. 
Inuzuka, M. A. \& Duarte, R. T. (2012). Produção de REA apoiada por MOOC. Disponível em www.artigos.livrorea.net.br/2012/05/producao-de-rea-apoiada-por-mooc/

Lemos, André (2004). Cibercultura e mobilidade: a era da conexão. Razón y Palabra, n. 41, out/nov. Disponível em www.razonypalabra.org.mx/anteriores/n41/alemos.html

Lévy, P. (1999). Cibercultura. Trad. C. I. Costa. São Paulo: Editora 34.

Mattos, Ana Carolina G. (2015). MOOC: um recorte de análise das produções nacionais e internacionais. Dissertação de mestrado. Universidade Federal de Juiz de Fora.

Peters, O. (2004). A educação a distância em transição: tendências e desafios. Trad. L. F. d. S. Mendes. $2^{a}$ ed. São Leopoldo: Editora Unisinos.

Pretto, N. L. (2012). Professores-autores em rede. In: B. Santana; C. Rossini; N. L. Pretto. Recursos educacionais abertos: práticas colaborativas e políticas públicas (pp. 91-108). São Paulo/Salvador: Casa da Cultura Digital/EDUFBA. Disponível em http://www.artigos.livrorea.net.br/2012/05/professores-autores-em-rede/

Rogers, C. R. (1997). Tornar-se pessoa. Trad. M. J. C. Ferreira. $5^{a}$ ed. São Paulo: Martins Fontes.

Santaella, Lúcia (2004). Culturas e arte do pós-humano: da cultura das mídias à cibercultura. In Valdir José de Castro (Coord.). $2^{\mathrm{a}}$ ed. São Paulo: Paulus.

Santos, A. I., Cobo, C. E. \& Costa, C. (2012a). Compêndio recursos educacionais abertos: casos da América Latina e Europa na Educação Superior. Rio de Janeiro: CEAD-UFF (edição trilíngue). Disponível em http:// www.oportunidadproject.eu/en/?option=com_content\&view=article\&id=122\&ltemid=438\&lang=en

Santos, A. I. (2012b). Educação Aberta: histórico, práticas e o contexto dos recursos educacionais abertos. In: B. Santana; C. Rossini; N. L. Pretto. Recursos educacionais abertos: práticas colaborativas e políticas públicas (pp. 71-89). São Paulo/Salvador: Casa da Cultura Digital/EDUFBA. Disponível em http://www. artigos.livrorea.net.br/wp-content/uploads/2012/05/REA-santos.pdf

Santos, A. I. (2011). Open Educational Resources in Brazil: State-of-the-art, Challenges and Prospects for Development and Innovation. Moscow: Unesco - Institute for Information Technologies in Education. Disponível em http://unesdoc.unesco.org/images/0021/002149/214975e.pdf

Santos, Edméa (2005). Educação online: cibercultura e pesquisa-formação na prática docente. Programa de Pós-graduação em Educação. Tese de doutorado. Universidade Federal da Bahia. Disponível em https://repositorio.ufba.br/ri/handle/ri/11800

Silva, Marco (2009). Educação presencial e online: sugestões de interatividade na cibercultura. In Eugênio Trivinho e Edilson Cazeloto (Orgs.). A cibercultura e seu espelho: campo de conhecimento e nova vivência humana na era da imersão interativa. São Paulo: ABCiber. Disponível em http://abciber.com/ publicacoes/livro1/textos/educacao-presencial-e-online-sugestoes-de-interatividade-na-cibercultura/ 